MATEC Web of Conferences 6, 02001 (2013)

DOI: $10.1051 /$ matecconf/20130602001

(C) Owned by the authors, published by EDP Sciences, 2013

\title{
Microstructural response of polypropylene fibres at high temperature to protect concrete from spalling
}

\author{
M.C. Alonso, V. Flor-Laguna and M. Sanchez \\ Institute of Construction Science Eduardo Torroja, (IETcc-CSIC), Madrid, Spain
}

\begin{abstract}
The microstructural analysis of the interfacial transition zone (ITZ) and the interaction of polypropylene fibres (PPF) with mortar in the temperature region 170 to $300{ }^{\circ} \mathrm{C}$ have been considered. The results confirm a mixed mechanism: The presence of the PPF alters the ITZ and favours an initial cracking formation. After melting, PPF diffuses in the surrounding cement paste closing micropores while, simultaneously, macro pores are increased as consequence of the free space leaved and the growing of microcracks.
\end{abstract}

\section{INTRODUCTION}

Several works have highlighted the positive effect of the introduction of polypropylene fibres (PPF) to prevent the risk of explosion of dense concretes under fire. However, the mechanism that contributes to this beneficial effect needs to be clarified in order to use PPF in optimal conditions (proportion and shape).

It is well known that polypropylene suffers several stages of degradation at high temperature. In a first stage at relatively low temperatures, around $160^{\circ} \mathrm{C}$, the polypropylene melts. The PPF remains in melted state in a temperature range that depends on the type of polypropylene, but usually varies from 160 to $350^{\circ} \mathrm{C}$. Besides, studies of the behaviour of polypropylene fibres at high temperature are focussed on the use of small fibres with diameters between 15 and $100 \mu \mathrm{m}$ and lengths between 6 and $30 \mathrm{~mm}$, in dosages from 0.5 to $3 \mathrm{~kg} / \mathrm{m}^{3}$.

The incorporation of microfibers to cementitious materials introduces alterations in their performance at high temperature. The size of these changes depends on the type and proportion of fibre employed and on the concrete properties [1,2]. It is accepted that the melting of PPF at relatively low temperatures $\left(150-200^{\circ} \mathrm{C}\right)$ contributes creating open paths for vapour release. But the degradation of the polypropylene with mass loss occurs at higher temperatures, above $250{ }^{\circ} \mathrm{C}$, varying with the type of polypropylene [1-3].

Although does not exist a conclusive known about how this type of fibres works, it has been demonstrated that their presence in concrete reduces the pore pressure at high temperature, associated with its melting ability creating hollows where the water steam is transported $[1,4]$ and relaxes vapour pressures. The permeability also increases by incorporating PP fibres, especially at temperatures near $170^{\circ} \mathrm{C}$, when melting occurs $[1,5]$.

One of the most studied parameters is that concerning the pore size evolution of concrete with PPF addition $[2,3,6-8]$ but no total agreement in the results is found. Increases in large pore sizes are generally addressed, but the melting of PPF does not represent a direct increase in capillary pores [2]. Besides, the nucleation of microcracking initiated in the channel of the PPF $[2,9]$ has been identified after melting, which has been associated with the expansion of the polypropylene melt, which would generate tensions leading to microcracks [1].

This is an Open Access article distributed under the terms of the Creative Commons Attribution License 2.0, which permits unrestricted use, distribution, and reproduction in any medium, provided the original work is properly cited. 


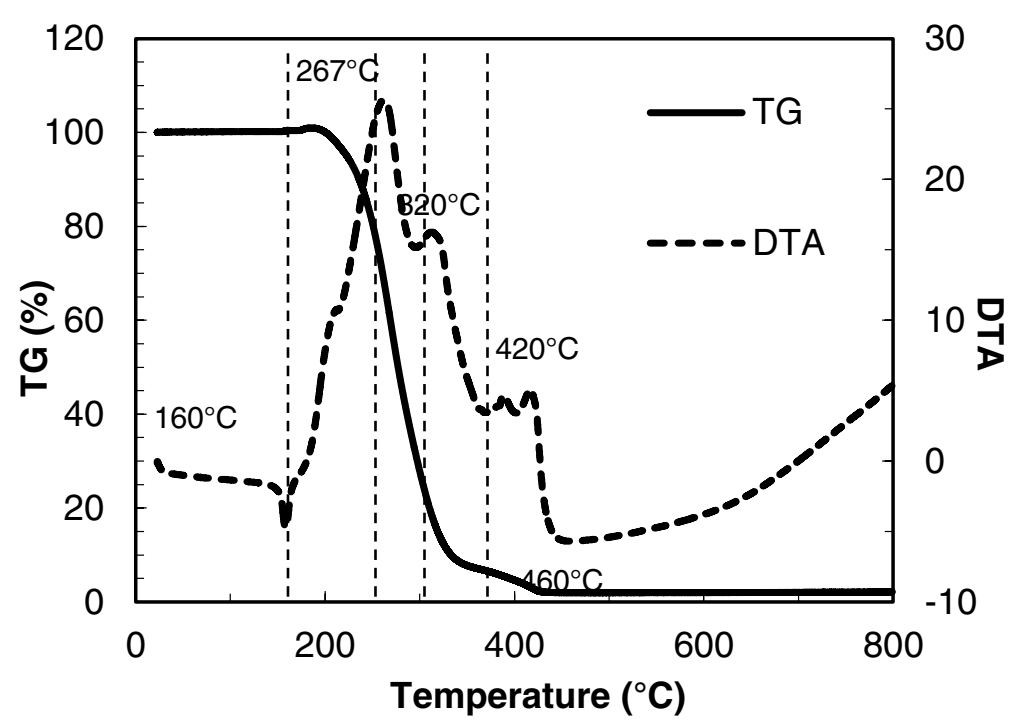

Figure 1. TG and DTA of PPF.

It has been also argued that the melting of the fibre creates pores at the fibre channel which is reflected in the mechanical properties with a slight decrease with respect the concrete without fibres $[5,10]$.

The above analysis of the results from different authors goes to the evidence that several mechanisms have been proposed for the thermal response of PPF in concrete at high temperature, although none of them have been fully demonstrated at microstructural level. Present work makes a study at micro and macro level in the region of temperatures where PPF are melted but present in the bulk of the concrete in order to address the reason for its beneficial effect in reducing the risk of spalling of concrete at high temperature.

\section{EXPERIMENTAL PROCEDURE}

Mortar specimens using OPC with water $/$ cement $=0.5$ and cement/sand $=1 / 3$ were prepared. Different dosages of PPF: $0,0.52$ and $0.80 \mathrm{~kg} / \mathrm{m}^{3}$ (equivalent to 0.06 and $0.09 \%$ in volume) were also added. The dimensions of the fibres were L: $6 \mathrm{~mm}$ and Diameter: $15 \mu \mathrm{m}$, the aspect ratio 400 . The volumes of PPF are below the percolation level [11], so the enhancement of the percolation level of the ITZ regions surrounding the aggregates is expected.

The thermal decomposition of the fibre was analysed using TG/DTA test and compiled in figure 1. The DTA shows that the critical transformation peaks initiate at $160^{\circ} \mathrm{C}$ with an endothermic peak related to the melting of the fibre, followed by series of exothermic peaks, between 200 and $450{ }^{\circ} \mathrm{C}$, related to progressive transformation of the fibre. From TG analysis it is important to point out that the progressive processes of transformation of PPF after melting are not developed with simultaneous mass loss (see TG in Fig. 1). The weight loss starts at temperatures above $250{ }^{\circ} \mathrm{C}$, at $350{ }^{\circ} \mathrm{C}$ around $90 \%$ weight loss has taken place and at $500{ }^{\circ} \mathrm{C}$ the PP is fully degraded. This thermal response of PPF will have a relevant contribution to control the spalling of concrete at high temperatures.

The heat treatments of fibred mortars were performed in an electric oven following a heating rate of $1^{\circ} \mathrm{C} / \mathrm{min}$, maintaining the selected temperature for two hours and cooling inside the oven. The range of temperature was selected from DTA/TG test were the fibre is evolving within the matrix of the heated concrete, the temperatures selected were: initial $\left(20^{\circ} \mathrm{C}\right), 170,200,250,300$ and $500^{\circ} \mathrm{C}$. 


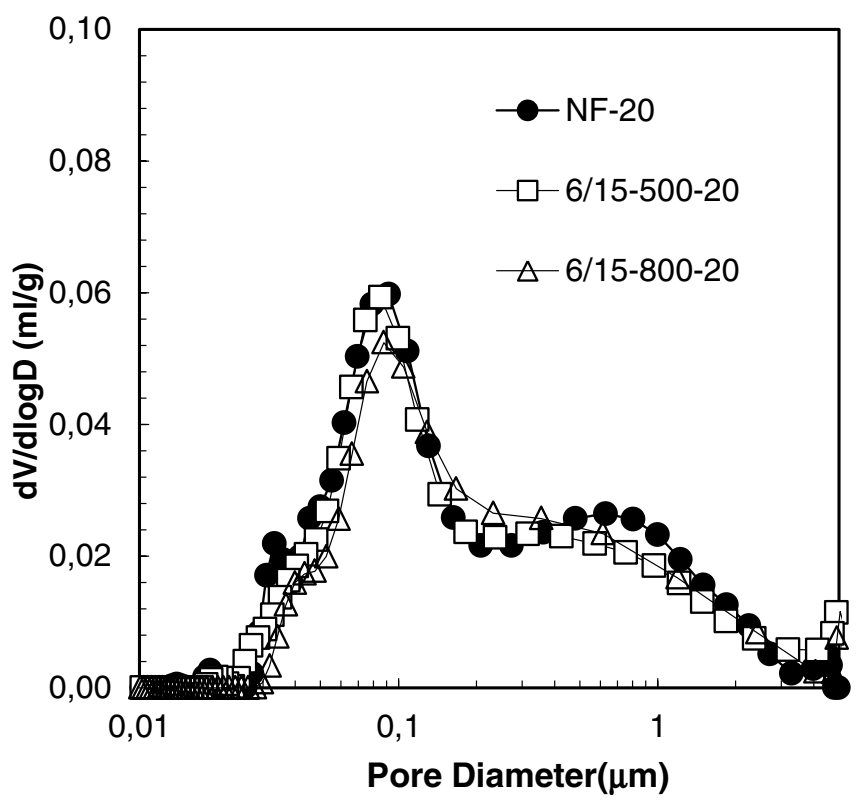

Figure 2. Micropores size distribution in initial mortar with and without PPF.

The microstructural changes in mortar induced by the PPF were analysed before and after heating. Porosity and pore size distributions were determined through mercury intrusion porosimetry. SEM using back scattering mode was also employed. The macrostructural changes were analysed determining the mechanical strength changes of mortars after cooling, in residual state, in samples of $4 \times 4 \times 16$ (compressive and flexural strength). The ultrasound rate variations were also evaluated.

\section{RESULTS AND DISCUSSION}

As commented in the introduction, a mechanism that explains satisfactory the benefit on the use of PPF to control the risk of spalling of concrete is not yet fully understood. Changes at microstructural level are expected, although their origin and propagation from micro to macrostructure has to be addressed, including from the initial interaction of the PPF with the matrix of the concrete and its further contribution in propagation or generation of new changes induced during heating due to thermal transformations, both in cement paste and PPF.

\subsection{Initial disturbances introduced by the PPF in the mortar matrix}

One of the first aspects to be clarified is related to the modifications due to PPF incorporation in the microstructure of the bulk of the concrete, in particular if additional percolation paths are nucleated from the initial state inside the ITZ on the cement paste and in the ITZ between aggregates and voids, as postulated in [11].

The analysis of the pore size distribution can contribute to highlight this aspect: capillary pore region, from 0.01 to $5 \mu \mathrm{m}$, is not altered with the presence of PPF, both with 0.06 and $0.09 \%$ in volume of PPF addition, as can be clearly observed in Figure 2. This region of pores exhibits the expected percolation transition of cement paste, as suggested by $[12,13]$.

On the other side, pore sizes from 5 to $100 \mu \mathrm{m}$ are highly altered due to the addition of PPF, as it is shown in Figure 3. The increase of PPF content increases the amount of macropores. Higher amount of 


\section{MATEC Web of Conferences}

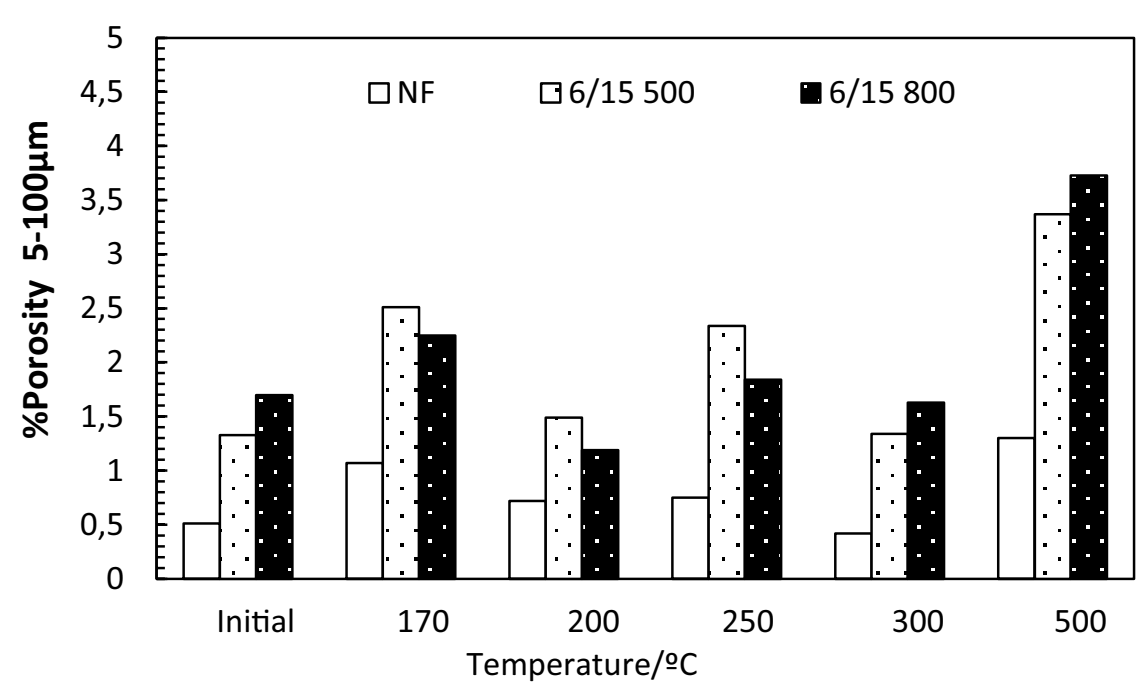

Figure 3. Macropores $(5-100 \mu \mathrm{m})$ variation in mortar with and without PPF in initial mortar and after several temperatures.

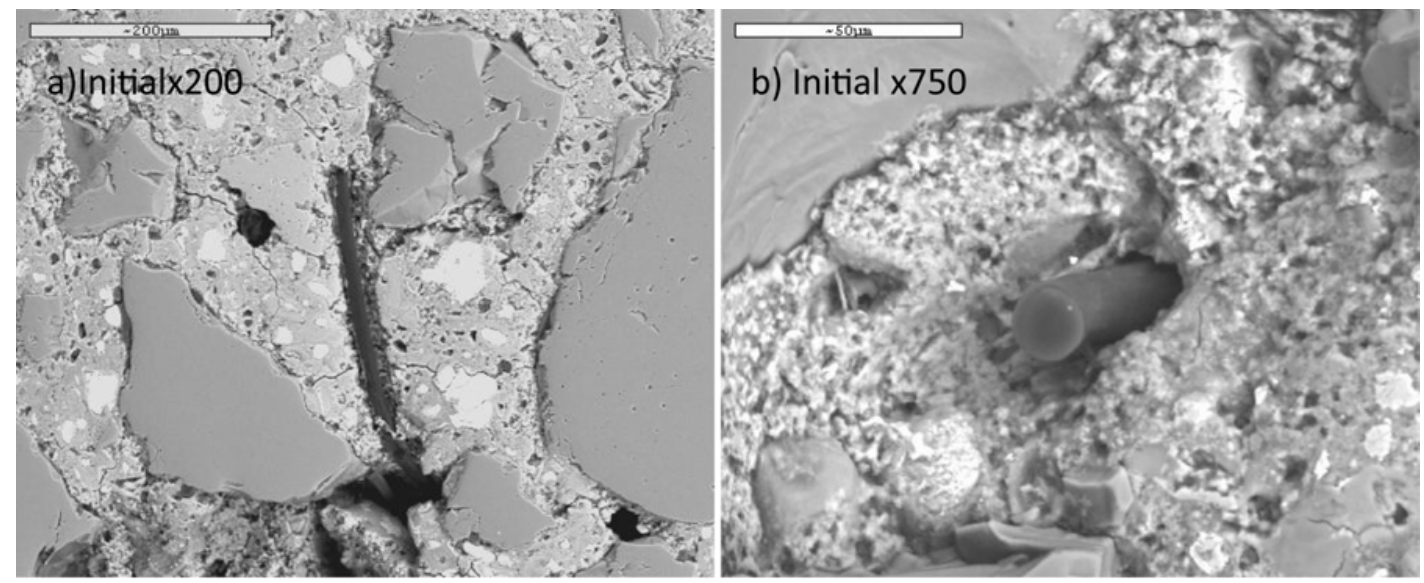

Figure 4. SEM microstructure of PPF distribution in the bulk of initial mortar (before heating). a) Microcracks, b) gap at ITZ PPF/cement paste and aggregate/cement paste.

pores are measured with PPF which suggests the formation of new paths to increase the percolation of zones of the ITZ between aggregates, voids and PPF, as suggested in [11].

This increase in percolation of the pore structure ( 2 or 3 times higher) due to PPF addition, also confirmed with SEM, Figure 4a-b, develops in two forms: 1) Growing of perpendicular microcracks from the fibre settlement through the neighbouring cement paste, Figure $4 a, 2$ ) formation of wide gaps at the interface of PPF/adjacent-cement paste, less relevant at the ITZ of the aggregate/cement paste, despite the higher aggregate size, as observed in figure $4 \mathrm{~b}$.

This particular interaction of PPF with the cement paste could have its origin in the hydrophobic ability of polypropylene surface that favours the accumulation of water at the interface of the fibre after mixing [14]. This hydrophobic property of polypropylene contributes to the generation of the microdamages at the interfacial cement paste, increasing the percolation of the zone. 


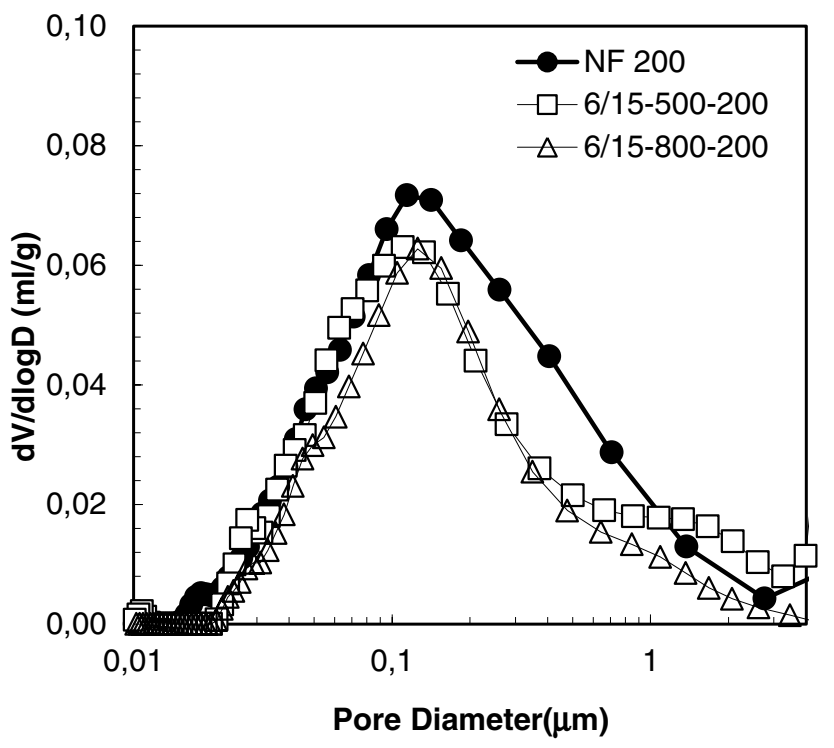

Figure 5. Pore size distribution of capillary pores after heating of mortars $\left(200^{\circ} \mathrm{C}\right)$.

\subsection{Evolution of microstructure of PPF/mortar due to thermal action}

Once the fibered mortar is exposed to temperatures above $100^{\circ} \mathrm{C}$, the dehydration of cement paste starts with the progressive destruction of $\mathrm{CSH}$ and loss of water followed by the subsequence increase in porosity [15]. PPF are not chemically altered before $160^{\circ} \mathrm{C}$, as deduced from Figure 1, although some negligible effect associated with the thermal expansion capacity has been proposed [1]. However, it is important to take into account that the expansion of polypropylene does not overpass $10 \%$ of the volume of the fibre and this could be absorbed by the fibre ITZ, Nevertheless, the increase of pre-existing microcraks cannot be neglected due to the combination of cement paste shrinkage and dehydration, increasing in this way the percolation at the PPF level. Some authors have also addressed this enhancement of microcraking but only confirmed after the melting of the fibre [2,9].

Above the critical temperature of $160^{\circ} \mathrm{C}$ the PPF melts. This thermal response of polypropylene also induces changes at microstructural level. In the pore structure two effects are detected: 1) decrease in capillary pores at all temperatures tested after melting of PPF, $170^{\circ} \mathrm{C}$ up to $300^{\circ} \mathrm{C}$, Figure 5 shows the case after $200^{\circ} \mathrm{C}$, even though dehydration of CSH generally causes pore increase in the cement paste with heating [15]. 2) increase in pore size content of the macropores region, as shown in Figure 3. After the total decomposition of PPF, this region of pores grows significantly due to the empty space at the fibre settlement. So, as the degradation of the PPF evolves with temperature, the percolation of the ITZ is increased at the macropores region, and the percolation of the ITZ from the cement paste near to the PPF settlement is decreased. The above results suggest that the beneficial effect of PPF for spalling control is a balance between percolation decrease in micropores and percolation increase of macropores.

The consequences of the changes in the pore structure due to heating were analysed with SEM. After $170{ }^{\circ} \mathrm{C}$ the PPF is melted and the ITZ at the channel of the fibered mortar is increased and also new microcracks perpendicular to the fibre have grown. Besides, some pores of the adjacent cement paste are polluted with polypropylene, which suggest that the melted fibre has flowed and has been absorbed by the mortar out of the fibre channel. This diffusion effect is more evident at higher temperatures as consequence of a viscosity decrease of the polypropylene with the increase of temperature [16] and can extend several mm outwards the fibre channel, as shown in Figure $6 \mathrm{~b}$. 

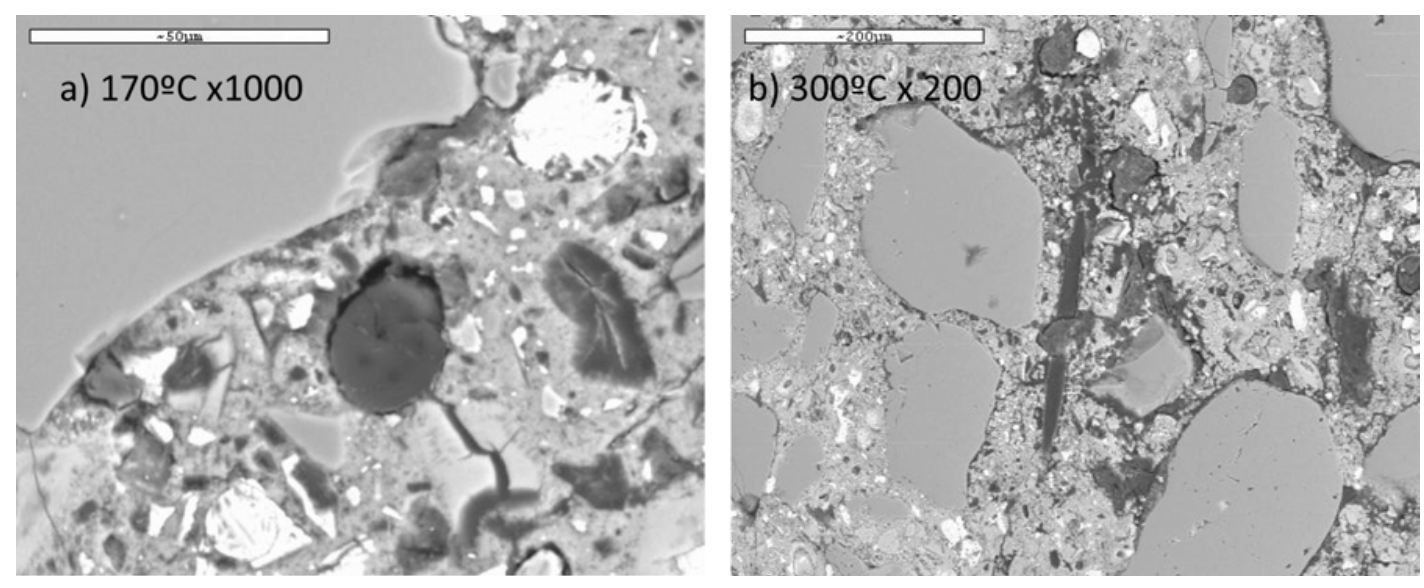

Figure 6. SEM microstructure of PPF in the bulk of mortar after heating. a) After $170{ }^{\circ} \mathrm{C}$, b) after $300^{\circ} \mathrm{C}$.
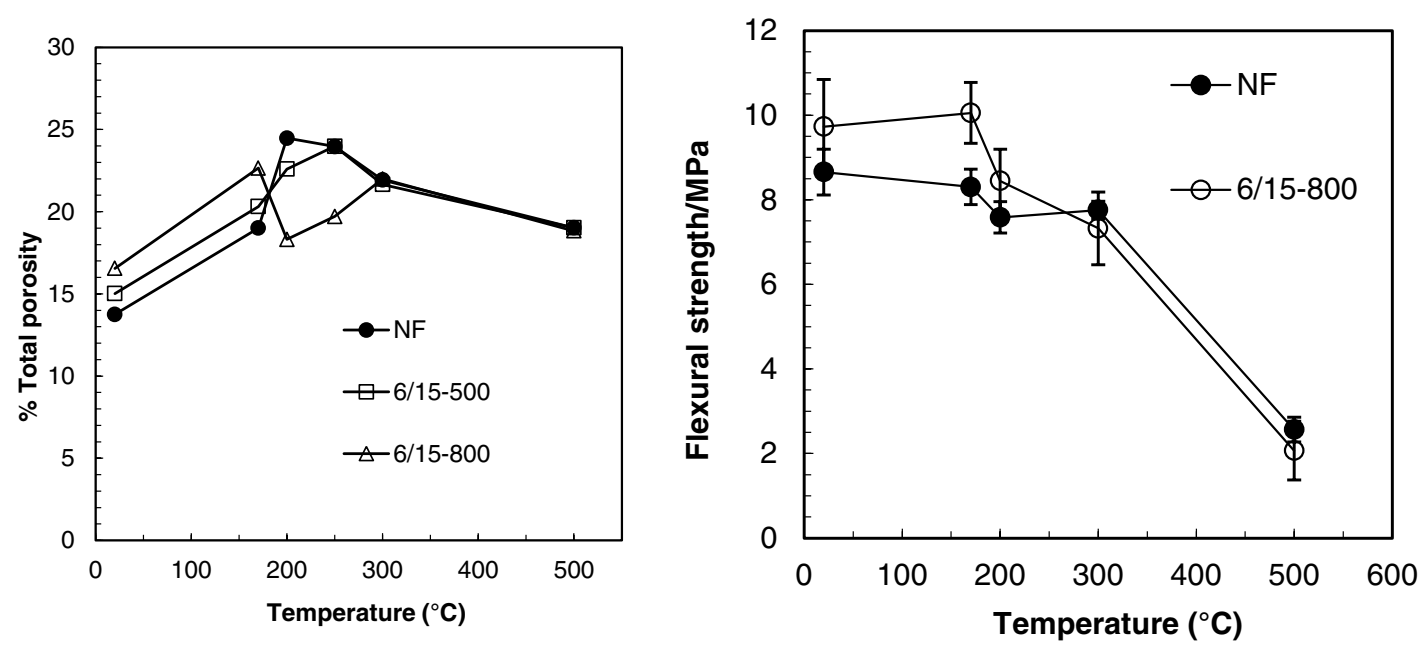

Figure 7. Changes after heating of mortar with and without PPF. Left) $\%$ total porosity, right) flexural strength.

These changes in the different regions of the pore structure due to the thermal action are also noticed in the total porosity, Figure 7-left. Higher porosity is always measured in the mortar containing PPF, but, while a continuous increase in porosity is detected in the mortar without PPF, a decrease is observed in the mortars with PPF after the melting point, more evident for the higher content of PPF used $0.09 \%$ in volume). After $300^{\circ} \mathrm{C}$ and $500^{\circ} \mathrm{C}$ the porosity of all materials approaches, due to the big influence of dehydration and alteration of cement paste that overlap its effect with that of the melted fibre. Changes are also appreciated at macrostructural level, although compressive strength is not significantly affected due to the addition of the PPF, in agreement with the no differences observed in micropores of Figure 2. Besides, the changes in macropores are not sufficient to alter negatively the mechanical properties due to the small size, $\mathrm{L} / \mathrm{D}$, of the fibre employed. Ultrasonic velocity gives similar information. The more relevant changes at macro level are observed with flexural strength, more efficient with PPF addition that begins to change after the melting of the fibre, losing its beneficial effect. 
IWCS 2013

\section{CONCLUSION}

Present study has allowed addressing the alterations observed in PPF mortar after high temperature exposure, to contribute to make more understandable the mechanism of concrete protection from spalling risk. The more relevant observations are:

- The addition of PPF changes the macropores of concrete. The increase of ITZ at the PPF/cement paste together with the formation of microcracking is the responsible for this increase.

- After melting of PPF, the micropores of the mortar are decreased due to the diffusion of the melted polypropylene and the absorption at the neighbourhood cement paste, but this effect is accompanied by a simultaneous increase of macropores due to the augment of the interfacial region of PPF channel and to the growing of microcracks.

\section{References}

[1] Kalifa, P., Chene, G. and Galle, C., High temperature behaviour with polypropylen fibres. From spalling to microestructure, Cem. and Conc. Rs., 31, 1487-1499, 2001.

[2] Alonso, C., Andrade, C., Menendez, E. and Gayo, E., Microstructural changes in high and ultrahigh performance concrete exposed to high temperature environments. ACI sp 229, Quality of concrete structures and recent advances in concrete materials and testing, Sept. 289-302, 2005.

[3] Zeiml, M., Leithner, D., Lackner R, Mang, HA, G., How do polypropylene fibers improve the spalling behaviour of in-situ concrete?, Cem and Conc. Rs. 36, 929-942, 2006.

[4] Bangi, M.R. and Horiguchi, T., Effect of fibre type and geometry on maximum pore pressures in fibred-reinforced high strength concrete at elevated temperatures, Cem. and Conc. Rs., 42, 459-466, 2012.

[5] Sofren Leo Suhaendi, Takashi Horiguchi, Effect of short fibers on residual permeability and mechanical properties of hybrid fibre reinforced high strength concrete after heat exposition, Cement and Concrete Research 36 (2006) 1672-1678.

[6] Klingsch, E. and Frangi, A, Experimental analysis on changes of the porosity of ultrahigh performance concrete at elevated temperature, 2cd Int RILEM WS on Concrete Spalling due to fire exposure (2011) 245-352.

[7] Huismann, S., Materialverhalten von hochfestem beton unter thermomechanischer beanspruchung, PhD, Fakultat fur bauingenieurwesen (2010).

[8] Liu, X, Ye, G, De Schutter, G., Yuan, Y. and Taerwe, L., On the mechanism of polypropylene fibres in preventing fire spalling in self-compacting and high-performance cement paste.

[9] Pistol, K., Weise, F., Meng B. and Schneider U., The mode of action of polypropylen fibres in high performance concrete at high temperatures, 2cd Int RILEM WS on Concrete Spalling due to fire exposure (2011) 289-296.

[10] Sideris K.K., Manita P., Chaniotakis E. "Performance of thermally damaged fibre reinforced concretes" Construction and Building Materials 23 (2009) 1232-1239.

[11] Bentz, D.P., Fiber percolation and spalling of high performance concrete, ACI Mat.J., 351-359, 2000.

[12] Powers, T.C., Capillary continuity or discontinuity in cement pastes, PCA Bulletin, 10, 2-12, 1959.

[13] Bentz, D.P. and Garboczi E.J., Percolation of phases in a three dimensional cement paste microstructural model, Cem. and Conc Rs., 21, 324-344, 1991.

[14] Haniche, R., Contribution à l'étude des bétons portés en température / Evolution des propriétés de transfert / Etude de l'éclatement. Univ. of Lion, PhD, Dec., 2011.

[15] Alonso, C. and Fernandez-Municio, F., Dehydration and rehydration processes of cement paste exposed to high temperature environments, J. of Material Science, 39, 3015-3024, 2004.

[16] Chen, IJ and Bogue, DC, Time -dependent stress in polymer melts and review of viscoelastic theory, Transactions of the society of rheology, 16, 1, 59-78, 1972. 